\title{
Study on Vocabulary Learning Strategies for Chinese English-Majors
}

\author{
Yougen Lou \\ Department of Foreign Studies Yangtze University Hubei Province, China \\ Email: louyougen@163.com
}

\begin{abstract}
This paper attempts to explore the overall pattern of English vocabulary learning strategies used by some Chinese English-majors. In addition, both similarities and differences in English vocabulary strategies used between male English-majors and female English-majors. 105 first-year English-majored students from Yangtze University participated in a vocabulary test, band 3 test and a questionnaire. The results show: (1) Chinese English-majors used a variety of English vocabulary learning strategies in vocabulary learning, including metacognitive, cognitive and social/affective strategies. (2)There are significant differences in using EVLS at metacognitive, social/affective levels between male English-majors and female English-majors.

Index Terms - Chinese EFL Graduate Learners, Learning Strategies, English Vocabulary Learning Strategies
\end{abstract}

\section{Introduction}

As we all know, one can master the grammar of the target language in the limited time, while one cannot grasp the vast vocabulary of one's native or a foreign language.

In the field: the English as foreign language, researchers, practitioners, and curricula designers are interested in one question. When everything else( including teaching materials, teaching methods and teachers) remains the same, however, why do individual English learners achieve different output levels. What leads to these differences? In order to look for the answers to these questions, researchers did study from the quest for improving teaching method, both in and out of classrooms, instead concentrating on how learners approach learning, and the kinds of strategies and cognitive processing they use in foreign language acquisition.

Vocabulary learning is the greatest stumbling block for most language learners. As an indispensable part of language system, vocabulary learning is of great importance to language acquisition. Vocabulary is a very important component of a language. One cannot learn a language without vocabulary[1]. The study of vocabulary is at the center of language learning and teaching. In a language, grammar provides the overall patterns, vocabulary the material to put in the patterns. No matter how well the student learns grammar, no matter how successfully he masters the sounds of a second language without words to express a wide range of meanings, communication in that language cannot reach any meaningful way. And Wilkins[2] observes "without grammar very little can be conveyed; without vocabulary nothing can be conveyed."

The purpose of this study was to investigate the vocabulary learning strategies used by Chinese EFL learners and their relationship to learning outcomes. More specifically, this study attempted to answer the following questions:

1) What types of strategies do Chinese English-majors tend to employ in learning vocabulary?

2) Are the vocabulary learning strategies used by male English-majors different from those used by female English-majors?

\section{Literature Review}

Research on learning strategies can be divided into three stages. The first stage concerns with identifying and listing all the strategies that foreign language learners used in their learning. In the second stage, researchers focus on classifying and giving definitions to strategies. The third stage deals with the effectiveness of learning strategies with their results most fascinating because there are many classifications and definitions.

The literature on learning strategies in foreign language learning emerged from a concern for identifying the characteristic of effective learners. Research focusing on the "good language learners" had identified strategies reported by students or observed in language learning situations that seemingly contributed to learning. These efforts demonstrated that students do apply learning strategies while learning a foreign language and these strategies can be described and classified. Therefore, many researchers[3] [4] [5] studied the identification and classification of learning strategies.

Influenced strongly by the findings of cognitive psychology, O'Malley and Chamot[5] considered learning strategies as cognitive skills. Learning strategies have been divided into three categories according to the level or type of processing involved[5]. They are meta-cognitive strategies, cognitive strategies, and social/affective strategies. Meta-cognitive strategies are higher order executive skills that may entail planning for, monitoring, or evaluating the success of a learning activity. Cognitive strategies operate directly on incoming information, manipulating it in ways that enhance learning. Social/affective strategies represent a broad grouping that involves either interaction with another person or ideational control over affect.

The following is the greatest differentiation and heaviest use in subcategories of planning strategies. 


\begin{tabular}{|c|c|}
\hline Learning Strategies & Description \\
\hline \multicolumn{2}{|l|}{ Metacognittive } \\
\hline Advanced organizers & Making a general but comprehensive preview of the concept or principle in an anticipated learning activity. \\
\hline Selective attention & $\begin{array}{l}\text { Deciding in advance to attend specific aspects of language input or situational details that will cue the } \\
\text { retention of language input. }\end{array}$ \\
\hline Delayed production & Consciously deciding to postpone speaking to learn initially through listening comprehension. \\
\hline Self-evaluation & Checking the outcomes of his language learning against an internal measure of completeness and accuracy. \\
\hline \multicolumn{2}{|l|}{ Cognitive } \\
\hline Translation & Using the first language as a base for understanding and/or producing the second language. \\
\hline Grouping & Reordering or reclassifying and perhaps labeling the material to be learned based on common attributes. \\
\hline Note-taking & $\begin{array}{l}\text { Writing down the main idea, important points, outline, or summary of information presented orally or in } \\
\text { writing. }\end{array}$ \\
\hline Deduction & Consciously applying rules to produce or understand the second language. \\
\hline Imagery & $\begin{array}{l}\text { Relating new information to visual concepts in memory via familiar easily retrievable visualization, phrases, } \\
\text { or locations. }\end{array}$ \\
\hline Auditory representation & Retention of the sound for a word or phrase, or longer language sequence. \\
\hline Key word & $\begin{array}{l}\text { Remembering a new word in the second language by: 1) identifying a familiar word in the first language that } \\
\text { sounds like or otherwise resembles the new word; 2) generating easily recalled images of some relationship } \\
\text { with the new word. }\end{array}$ \\
\hline Inferencing & $\begin{array}{l}\text { Using available information to guess meanings of new items, predict outcomes, or fill in missing } \\
\text { information. }\end{array}$ \\
\hline \multicolumn{2}{|l|}{ Social/affective } \\
\hline Cooperation & Working with one or more peers to obtain feedback, pool information, or model a language activity. \\
\hline Question for classification: & Asking a teacher or other native speaker for repetition, paraphrasing, explanation, and/or examples. \\
\hline \multicolumn{2}{|c|}{ (O’Malley and Chamot's classification of learning strategies, 1990) } \\
\hline
\end{tabular}

\section{Research Methods}

\subsection{Subjects}

In September 2010,105 first-year English-majors were from 5 classes in the school of foreign studies, Yangtze University responded to the Vocabulary Learning Strategies Questionnaire. Among the 105 subjects, 69 were females and 36males, average age 19 with Chinese as the main language. They often complained about the burden of memorizing new words and the easy-forgetting characteristic of remembering. They often demand effective vocabulary learning strategies from teachers as they consider a large vocabulary is essential to language learning.

\subsection{Instruments}

The instruments used in the study were one questionnaire, the other the vocabulary test

\subsubsection{Questionnaire}

The Vocabulary Learning Strategies Questionnaire, written in Chinese, consists of two parts: One is concerned with personal profiles that is: name, age, and sex, major. The other part consists of 20 statements concerning vocabulary learning behaviors, which are divided into three major parts: metacognitive strategies, cognitive strategies and social/affective strategies. The students indicated their opinions in terms of a five-point scale from 'this statement is 
never or almost never true of me' (1) to 'this statement is completely or almost completely true of me '(5). The design of the questionnaire is based on O'Malley and Chamot's (1990) classification of learning strategies ${ }^{[5]}$. Questionnaires were distributed to students and completed in class. We collected 105 valid questionnaires.

\subsubsection{Vocabulary Test}

The author had intended to design all parts of the vocabulary test by himself but found it very difficult. It may take a long time. So the author chose vocabulary from A Modern English Course (published by Foreign Language Teaching and Research Press). The vocabulary test was held in class for students to complete in 30minutes.

\subsection{Data Collection and Analyses Procedures}

Data collection was conducted through the questionnaire and the vocabulary test. The questionnaires were written in Chinese and handed out to the students during the class session so as to save time and avoid ambiguity in understanding, and if any, the teachers would be of help. The vocabulary test was given to them immediately after the questionnaires were finished and then the two parts are collected. Scores were summed up according the total number of participants' correct responses in the test.

The results of the questionnaire and scores tests are inputted to computer and SPSS+13.0 statistical analysis was adopted to make analyses. Descriptive statistics was obtained to summarize the overall patterns of vocabulary learning strategies used by these students. Thereupon, a T-test is performed to examine the differences in using vocabulary learning strategies between male English-majors and female English-majors. The answers to the strategies listed in the questionnaire are designed in 5point Likert-Scale. A mean score above 3 indicates high frequency in the use of the corresponding strategy while a mean score below 3 represents low frequency.

\section{Results and Analyses}

\subsection{Results of English Vocabulary Learning Strategies}

The first investigated question is what the whole pattern of EVLS employed by the Chinese English-majors investigated. The questionnaire is a Five-point scale, so a mean score which is above 3 indicates high frequency in the use of corresponding strategy while a mean score is below 3 , which represents low Frequency in the use of the strategy. The higher the mean score is, the more often the strategy is used. In order to determine how they avail themselves to each vocabulary learning strategy, average mean score and standard deviation and strategies use at three levels are calculated (see table 1 and table 2)

Table1 shows that the general descriptive statistics of metacognitve strategies, cognitive strategies and social/affective strategies. Among the three dimensions of English vocabulary learning strategies, metacognitve strategies $($ Mean=3.57, S.D=1.03), which suggests that English-majors often adopt metacognitive strategies to help themselves to learn English vocabulary; then cognitive strategies (Mean=3.30, S.D=1.168) which means that English-majors adopt cognitive strategies to help themselves to learn English vocabulary. Yet social/affective strategies ranks lowest $($ Mean= 2.69, $\mathrm{S} . \mathrm{D}=1.05)$, which suggests that English-majors adopt less social/affective strategies to help themselves to learn English vocabulary.

Table 1 Mean and standard deviation of metacognitve strategies, cognitive strategies and social/affective strategies

\begin{tabular}{|c|c|c|}
\hline Dimensions & Mean & S.D. \\
\hline Metacognitive Strategies & 3.57 & 1.03 \\
\hline Cognitive Strategies & 3.30 & 1.18 \\
\hline Social/Affective Strategies & 2.69 & 1.05 \\
\hline
\end{tabular}

And table 2 shows that the descriptive statistics on the use of each strategy at the three dimensions.

Firstly, strategy use is at metacognitive Level. It is obvious that selective attention( Mean $=3.48, \quad \mathrm{~S} . \mathrm{D}=1.04$ ) is the highest rank among the four categories of metacognitve strategies, which indicates that the investigated subjects are positive with regard to identifying important to-be-learned words and thus sparking their consciousness to acquire these words. Learner autonomy (Mean=3.18, S.D=1.05), which means English-majors can learn English vocabulary autonomy. Planning (Mean=3.10, S.D=1.18), which means English-majors adopt often to plan their English vocabulary learning. Self-evaluation (Mean=3.08, S.D=1.06), which means English-majors can evaluate their English vocabulary for them to have time make changes about vocabulary learning. Reasons to account for the English-majors metacognitive strategies are that English-majors are totally adults who know how to put their attention, learn English vocabulary autonomy without pushing them to learn, and make a plan to learn vocabulary then evaluate their learning procedure by themselves.

Secondly, strategy use is at cognitive strategies level. From table 2, we can see that the rank order of English vocabulary learning strategies at cognitive level is translation, dictionary looking-up, repetition, word formation, contextualization, imagery, grouping, keyword strategies. It is evident that translation (Mean=3.70, S.D=1.15) ranks the highest among all the English vocabulary learning strategies at cognitive stage, in other words, which means that English-majors use translation as the most frequently English vocabulary learning strategy. Next followed by dictionary looking-up (Mean=3.41, S.D=1.05) appears as the second frequently used cognitive strategy, which suggest that English-majors often learn the new words with the help of a dictionary. Repetition (Mean=3.18, S.D=1.27) is used by the more investigated subjects and it is evident that repetition demonstrates that more of the investigated subjects still have the conventional belief that vocabulary could be remembered via repetition that is related to rote learning. This belief has deep roots in traditional Chinese ideas about learning. This conventional way of teaching and learning still has a powerful influence in China nowadays. So it is natural to find the root 
in modern English teaching and learning in university. At the same time, it should be noted that some other mnemonic strategies including: grouping(Mean=3.07,S.D=1.05) means that the investigated subjects learn vocabulary by group vocabulary into different classification; Contextualization (Mean=3.05,S.D=1.01) suggest that students can guess the meaning of the new words with the help of the context; word formation (Mean=3.10 S.D.=1.03) means the investigated subjects use it to help them learn English vocabulary; imagery (Mean=2.81,S.D=1.04) means students seldom use their imagery to help them learn the new words; keyword (Mean=2.19, S.D=1.06) suggests that students seldom use it to learn vocabulary. The higher value of dictionary looking-up indicates that the investigated subjects are becoming the mature dictionary users, which might be introduced by the relatively poor English foreign language learning environment in China. The investigated subjects comparably make more use of contextualization strategies when learning new words. Language proficiency may play an even greater role in determining a vocabulary strategies' effectiveness. When learners' language proficiency reaches the threshold, some English learning strategies will be effective, such as guessing the new words' meaning from the context, using word formation to remember new words.

Finally, Social/Affective strategies are concerned, group work (Mean=3.16, S.D=.94) ranks higher than affective control (Mean=3.06, S.D=0.99). English majors could be as a group to discuss a topic.

Table 2 Mean and standard deviation of strategies use at three levels

\begin{tabular}{|c|c|c|c|}
\hline Dimensions & Categories & Mean & S. D. \\
\hline \multirow{4}{*}{$\begin{array}{c}\text { Metacognitie } \\
\text { Strategies }\end{array}$} & Selective attention & 3.48 & 1.04 \\
\cline { 2 - 4 } & Learner autonomy & 3.18 & 1.05 \\
\cline { 2 - 4 } & Planning & 3.10 & 1.18 \\
\cline { 2 - 4 } & Self-evaluation & 3.08 & 1.06 \\
\hline \multirow{4}{*}{$\begin{array}{c}\text { Cognitive } \\
\text { Strategies }\end{array}$} & Word formation & 3.10 & 1.03 \\
\cline { 2 - 4 } & DictionaryLooking-up & 3.41 & 1.05 \\
\cline { 2 - 4 } & Keyword & 2.19 & 1.06 \\
\cline { 2 - 4 } & Grouping & 3.07 & 1.05 \\
\cline { 2 - 4 } & Imagery & 2.81 & 1.04 \\
\cline { 2 - 4 } & Repetition & 3.18 & 1.27 \\
\cline { 2 - 4 } & Translation & 3.70 & 1.15 \\
\hline Social/Affective & Contextualization & 3.05 & 1.01 \\
\cline { 2 - 4 } Strategies & Group work & 3.16 & .94 \\
\cline { 2 - 4 } & Affective control & 3.06 & .99 \\
\hline
\end{tabular}

The results are generally equal to those of $\mathrm{Gu}$ and Johson's [6] study except the following parts: one is the present study shows that the English-majors investigated are more positive in using the metacognitive strategy-selective attention than learner autonomy at metacognitive strategy, which is in contrast with $\mathrm{Gu}$ and Johson's study; the other is that the present study indicates that rote learning strategies(repetition) plays an important role in students' vocabulary learning process while $\mathrm{Gu}$ and Johson's study suggests that students don't value rote learning as highly as other strategies. The difference may result from the difference of the investigated subjects.

The results of the present study show that students use the mother language as the mediator (translation) to acquire the new words and seem to look down on the value of keyword strategy.

\subsection{Results of t-test}

All the data from the questionnaires were typed and checked, we used SPSS+13.0 to calculate the mean scores and confirmed that the data were of or close to normal distribution. Then we carried out the independent sample t-test to measure the significant differences in metacognitive strategies, cognitive strategies and social/affective strategies between the female English-majors and the male English-majors. The significant differences occur only when the probability $(\mathrm{P})$ is below or equal to .005 .

Table 3 results of t-test

\begin{tabular}{|c|c|c|}
\hline & Learners Strategies & Sig(2-tailed) \\
\hline \multirow{4}{*}{ Meta. } & & $\mathrm{P}$ \\
\cline { 2 - 3 } & Selective attention & .875 \\
\cline { 2 - 3 } & Learner autonomy & $.002^{* *}$ \\
\cline { 2 - 3 } & Planning & $.003^{* *}$ \\
\hline \multirow{5}{*}{ Cog. } & Self-evaluation & .005 \\
\cline { 2 - 3 } & Word formation & .018 \\
\cline { 2 - 3 } & DictionaryLooking-up & .778 \\
\cline { 2 - 3 } & Keyword & .808 \\
\cline { 2 - 3 } & Grouping & .091 \\
\cline { 2 - 3 } & Imagery & .069 \\
\cline { 2 - 3 } & Repetition & .893 \\
\cline { 2 - 3 } & Translation & .696 \\
\hline \multirow{3}{*}{ Soc./Aff. } & Contextualization & .075 \\
\cline { 2 - 3 } & Group work & $.002 * *$ \\
\hline
\end{tabular}

From table 3, we can see that 1) Using strategies is at the metacognitive level. In the strategy of selective attention, $\mathrm{P}=.975$, which means there is no significant difference in the strategy of selective attention, indicating that students from the male and female groups both use this strategy. In the strategy of learner autonomy, $\mathrm{P}=.002$, which means there is a significant difference between the male and female groups, indicating that male English-majors and female English-majors have difference in learning autonomy. In the strategy of planning $(\mathrm{P}=.003)$ and the strategy of self-evaluation $(\mathrm{P}=005)$ are of significant differences. Therefore, we can conclude that female English-majors use more strategies when they learn English vocabulary.2) Using strategies is at the cognitive level. In the strategies of word formation $(\mathrm{P}=.018)$, dictionary looking-up $(\mathrm{P}=.678)$, keyword $(\mathrm{P}=.708)$, grouping $(\mathrm{P}=.091)$, imagery $(\mathrm{P}=.069)$, repetition $(\mathrm{P}=.893)$, translation $(\mathrm{P}=.696)$, contextualization $(\mathrm{P}=.075)$, there are no significant differences between the male and female groups. It indicates that both female and male 
English-majors use detailed strategies to learn vocabulary.3) Using strategies is at the social/affective level. Both the strategy of group work $(\mathrm{P}=.002)$ and the strategy of affective control $(\mathrm{P}=.003)$ are significant difference, which mean that female English-majors are good at group work to learn vocabulary and good at controlling themselves to learn vocabulary.

\section{Conclusion}

This study is designed to explore the overall pattern of EVLS employed by some English-majors in China. In addition, the employment of strategies and different strategies use between female English-majors and male English-majors.

105 first-year non-English-majored English-majors from the school of foreign studies in Yangtze University participated in a questionnaire and a vocabulary test. The questionnaire is used to investigate students who used English vocabulary learning strategies (EVLS) at metacognitive, cognitive and social/affective level. The results show: (1) Chinese English-majors used a variety of English vocabulary learning strategies in vocabulary learning, including metacognitive, cognitive and social/affective strategies.(2) There are significant differences in using EVLS at metacognitive, social/affective levels between female English-majors and male English-majors.

\section{Acknowledgment}

Yougen Lou thanks you, ICMESS 2014 Organizing Committees and the publisher for your service and devotion.

\section{References}

[1] Krashen, S. 1989. We acquire vocabulary and spelling by reading: Additional evidence for the Input Hypothesis

[2] Wilkins, A. 1972. Linguistics in Language Teaching. Cambridge: MA: MIT Press

[3] Naimen, N., M..Frohlich, \& A. Todesco. 1975. The good language learner. TESL TALK6(1):58-75

[4] Rubin, J. (1985). What the "good language learner" can teach us. TE'SOL Quarterly 9(1):41-51

[5] OMalley, J. A.Chamot, 1990. Learning strategies in Second Language Acquisition. Cambridge University Press

[6] Gu, P. Y. \& R. K. Johnson. 1996. Vocabulary learning strategies and language learning outcomes. Language Learning46(4):643-79 